Glycerinsäure, ein Product der freiwilligen Zersetzung des Nitroglycerins;

von Warren de la Rue und Hugo Miller.

Vor einigen Jahren machten wir die Beobachtung, dals Nitroglycerin, welches nach der Methode von De Vry dargestellt und von aller anhängenden Säure sowohl als von überschüssigem Glycerin befreit war, im Laufe des Sommers, während dessen die Temperatur unseres Laboratoriums auf circa $30^{\circ} \mathrm{C}$. stieg, sich allmälig zersetzte.

Diese Entmischung machte sich zuerst durch eine grünliche Färbung bemerklich, welche das Nitroglycerin annahm; es entwickelten sich salpetrige Dämpfe, denen bald eine reichliche Gasentwicklung folgte. Im Laufe von einigen Monaten war der grölste Theil des Nitroglycerins verschwunden und das Gefäls mit Krystallen und einer leicht in Wasser löslichen dicklichen Flüssigkeit angefültt.

Wir untersuchten damals die Producte dieser Umsetzung, und fanden, dafs die ausgeschiedenen Krystalle reine 0xalsäure weren. Die Mutterlauge, welche aufser Oxalsäure und Salpetersäure noch eine dickflüssige Substanz enthielt, wurde, um die weitere Abscheidung der Oxalsäure und Salpetersäure zu bewirken, mit kohlensaurem Baryt gesättigı, der ausgeschiedene oxalsaure Baryt abfiltrirt und die Flüssigkeit allmälig eingedampft, wodurch fast aller salpetersaurer Baryt nach und nach abgeschieden wurde. Die endlich syrupdick gewordene Flüssigkeil wurde nunmehr über Schwefelsäure stehen lassen und trocknete da zu einer vollkommen amorphen glasigen Masse ein. Diese amorphe Masse enthielt eine erhebliche Menge Baryt an eine organische Säure gebunden. Zum Zweck des Wiederauflösens mil wenig Wasser 
ein Product der freiwilligen Zersetzung des Nätroglycerins. 123

übergossen, wurde sie weils, und indem sich ein Theil löste, schied sich ein anderer als weifser krystallinischer Körper aus. Diese krystallinische Substanz war ziemlich leicht in Wasser löslich und schied sich beim Eindampfen über Schwefelsäure in traubigen, aus Blättchen bestehenden Krystallaggregaten aus, welche unlöslich in Alkohol waren und beim Erhitzen schmolzen, sich stark aufblahten und den Geruch wie verkohlender Weinstein entwickelten.

Das mehrmals umkrystallisirte Salz verlor über Schwefelsäure getrocknet fast Nichts an Gewicht.

Eine Barytbestimmung gab für 0,5324 Substanz 0,3560 schwefelsauren Baryt, entsprechend 39,33 pC. Baryum.

Eine zweite Analyse des bis zum Schmelzen erhitzten und in der Wärme getrockneten Salzes gab für 0,6830 Substanz 0,4610 schwefelsauren Baryt, entsprechend 39,70 pC. Baryum.

Die aus dem Barytsalz abgeschiedene Säure bildele einen dicken Syrup und konnte nicht krystallisirt erhalten werden.

Die abgeschiedene Säure mit kohlensaurem Kupfer gesättigt, bildete eine blaugriine Lösung, die zu einer amorphen sehr Iöslichen Masse eintrocknete, welche unter Umständen krystallisirte. Beim Kochen schien sich die Lösung zu zersetzen, indem Kupferoxydul ausgeschieden wurde.

Die bei der Darstellung des krystallisirten Barytsalzes crhaltene Mutterlauge konnte nicht krystallinisch erhalten werden. Sie enthielt ebenfalls ein Barytsalz; da es aber nicht in bestimmter Form und frei von der vorhergehenden Verbindung erhalten werden konnte, wurde es nicht weiter untersucht.

Die Säure des krystallisirten Barytsalzes war demnach das einzige Product dieser Zersetzung des Nitroglycerins, welches einiges Interesse zu haben schien; da jedoch die erhallene Menge nur gering war und die Darstellung nicht 
sogleich wiederholt werden konnte, so unterblieb damals bis auf Weiteres die genauere Untersuchung dieses Gegenstandes.

Neuerdings ist nun von Debus und von Socoloff die Einwirkung der Salpetersäure auf das Glycerin studirt und unter den Producten die Säure $\mathrm{C}_{6} \mathrm{H}_{6} \mathrm{O}_{8}$ aufgefunden worden. Die Veröffentlichung dieser Untersuchungen brachte uns die eben beschriebenen Beobachtungen wieder in $\mathrm{Er}$ innerung, und es bedurfte wohl kaum mehr eines weiteren Beleges für die Identität unserer Säure mit der Glycerinsäure. Dessenungeachtet aber haben wir mit dem Rest unseres Präparates noch einige Versuche angestellt, deren Resultate die letzten Zweifel in dieser Beziehung ausschliefsen.

Da unter den beschriebenen Salzen der Glycerinsäure das Kalksalz am besten charakterisirt erschien; so zersetzten wir unser Barytsalz mit Oxalsäure und sättigten die Lösung mit kohlensaurem Kalk. Durch Abdampfen und Zusalz einer geringen Menge Alkohols zur Beförderung der Krystallisation schied sich das Kalksalz in schönen blätterigen Krystallen mit allen den Eigenschaften aus, welche Debus und Socoloff diesen Salzen zuschreiben.

Die Analyse des so erhaltenen Kalksalzes gab folgende Zahlen :

I. 1,2710 lufttrockenes Salz verloren, längere Zeit bis zum Schmelzen und dann auf $160^{\circ}$ erhitzt, 0,1759 Wasser und gaben 0,4370 kohlensauren Kalk, welche Zahlen 13,83 pC. Wasser und 13,75 pC. Calcium entsprechen.

Il. 0,4546 desselben Salzes, längere Zeit über Schwefelsäure bei gewöhnlicher Temperatur getrocknel und mit chromsaurem Blei vermischt verbrannt, gaben 0,4205 Kohlensäure, entsprechend 25,22 pC. Kohlenstoff, und 0,2077 Wasser, entsprechend 5,07 pC. Wasserstoff. 
ein Product der freiwilligen Zersetzung des Nitroglycerins. 125

Die von Debus für dieses Salz aufgestellte Formel $\mathrm{C}_{6} \mathrm{H}_{5} \mathrm{CaO}_{8}+2 \mathrm{HO}$ verlangt :

\begin{tabular}{lrrrc} 
& & & & Analysen \\
Kohlenstoff & 6 & 36 & 25,17 & $\mathbf{2 5 , 2 2}$ \\
Wasserstoff & 7 & 7 & 4,89 & 5,07 \\
Calcium & 1 & 20 & 13,98 & 13,75 \\
Sauerstoff & 10 & 80 & 55,96 & - \\
\cline { 3 - 5 } & & 143 & $100,00$. &
\end{tabular}

\section{Notiz über Selencyanallyl.}

Es war nicht unwahrscheinlich, dafs es ein Senföl geben könne, worin der Schwefel durch Selen vertreten ist $=$ $\mathrm{C}^{6} \mathrm{H}^{5}, \mathrm{C}^{2} \mathrm{NSe}^{2}$. Es mufste durch wechselseitige Zersetzung von Jodpropylen, $\mathrm{C}^{6} \mathrm{H}^{5} \mathrm{~J}$, und Selencyankalium erhalten werden. Hierüber liefs ich von Hrn. Tycho Schiellerup einige Versuche machen. $\mathrm{Er}$ fand, dafs durch schweflige Säure kalt gefälltes rothes Selen mit Leichtigkeit von einer Lösung von Cyankalium aufgelöst wird, dafs also diefs die einfachste Art ist, sich Selencyankalium zu verschaffen. Enthält das Cyankalium cyansaures Salz, so braucht man die Lösung nur zu kochen, um dieses zu zerstören; das Selencyankalium kann dann durch Alkohol vom kohlensauren Kali getrennt werden.

Eine Auflösung von reinem Salz in Alkohol warde nach gleichen Aequivalentgewichten mit Jodpropylen im Wasserbade der Destillation unterworfen, in einem Apparate, der 12 Stunden lang das Zurückfliefsen des sich condensirenden Products gestattete. Dann wurde es abdestillirt und mit Wasser vernischt. Es schied sich ein gelbes, im Wasser 